\title{
Regional Characteristics of Future Changes in Snowfall in Japan under RCP2.6 and RCP8.5 Scenarios
}

\author{
Hiroaki Kawase $^{1}$, Akihiko Murata ${ }^{1}$, Ken Yamada ${ }^{2,1}$, Tosiyuki Nakaegawa ${ }^{1}$, Rui Ito ${ }^{3,1}$, \\ Ryo Mizuta ${ }^{1}$, Masaya Nosaka ${ }^{1}$, Shunichi Watanabe ${ }^{1}$, and Hidetaka Sasaki ${ }^{1}$ \\ ${ }^{1}$ Meteorological Research Institute, Japan Meteorological Agency, Tsukuba, Japan \\ ${ }^{2} J a p a n$ Meteorological Agency, Tokyo, Japan \\ ${ }^{3}$ Japan Meteorological Business Support Center, Tsukuba, Japan
}

\begin{abstract}
We investigate regional characteristics of future changes in snowfall in Japan under two emission scenarios-RCP2.6 and RCP8.5-using a high-resolution regional climate model with $5 \mathrm{~km}$ grid spacing and discuss the influence of changes in atmospheric circulation. The high-resolution model can simulate details of changes in distributions of total snowfall in Japan. Under RCP2.6, the annual total snowfall decreases in most parts of Japan except for Japan's northern island, Hokkaido. In Hokkaido, the winter snowfall increases even under RCP8.5, especially in January and February. The snowfall peak is delayed from early December to late January in Hokkaido. Along the Sea of Japan in eastern Japan, the winter-total snowfall decreases even if the winter mean temperature is below $0^{\circ} \mathrm{C}$ in the future climate. The different snowfall changes in Hokkaido and on the Sea of Japan side of eastern Japan are caused by precipitation changes in each region. Future changes in atmospheric circulation related to the Aleutian low cause the enhancement and the inhibition of winter precipitation in Hokkaido and the Sea of Japan side of eastern Japan, respectively, contributing to changes in the regional characteristics of snowfall and snow cover in addition to moistening due to atmospheric and ocean warming.
\end{abstract}

(Citation: Kawase, H., A. Murata, K. Yamada, T. Nakaegawa, R. Ito, R. Mizuta, M. Nosaka, S. Watanabe, and H. Sasaki, 2021: Regional characteristics of future changes in snowfall in Japan under RCP2.6 and RCP8.5 scenarios. SOLA, 17, 1-7, doi:10.2151/ sola.2021-001.)

\section{Introduction}

Global warming due to an increase in anthropogenic greenhouse gases influences snowfall and snow cover (Hock et al. 2019; Meredith et al. 2019). Understanding future changes in annual total snowfall and maximum snow water equivalent is important as it is related not only to water resources and winter tourism but also to natural hazards such as full-depth avalanches. Short-term heavy snowfall also causes surface avalanches, poor visibility, and traffic disturbances. According to the Clausius-Clapeyron relationship, $1 \mathrm{~K}$ of warming induces a $7 \%$ increase in water vapor, resulting in increased precipitation if relative humidity and atmospheric circulations do not change significantly. In contrast, if the temperature exceeds $0^{\circ} \mathrm{C}$ due to global warming, snowfall will change to rainfall, and snow melting will accelerate. The paradox between the snowfall decrease due to warming versus the snowfall increase due to moistening is a key topic when we focus on future snow changes.

The winter mean surface air temperature is a key factor in tackling the snowfall paradox. In the coastal areas of the Sea of Japan (SoJ), where the winter mean temperature above the freezing point, a large reduction of snow cover has been projected (Inoue and Yokoyama 2003; Hosaka et al. 2005; Hara et al. 2008;

Corresponding author: Hiroaki Kawase, Meteorological Research Institute, 1-1, Nagamine, Tsukuba 305-0052, Japan. E-mail. hkawase@mri-jma.go. jp.

(C) The Author(s) 2021. This is an open access article published by the Meteorological Society of Japan under a Creative Commons Attribution 4.0 International (CC BY 4.0) license (http://creativecommons.org/license/by/4.0).
Kawase et al. 2013). Snowfall is projected to decrease in most parts of the world, as with the Japan's coastal areas, while it can increase in very cold regions where the winter mean temperature is below $-20^{\circ} \mathrm{C}$, such as Siberia (Brown and Mote 2009; Räisänen and Eklund 2012). High mountainous areas in middle latitudes, such as the Rocky Mountains and the European Alps, are also extremely cold regions where the winter mean air temperature is much lower than the freezing point. The annual snowfall is enhanced at higher elevations over the Colorado Headwaters of the Rocky Mountains in the future climate (Rasmussen et al. 2011, 2014). Even in Japan, mid-winter snowfall can increase over the high mountains above $2,000 \mathrm{~m}$ in central Japan in heavy snowfall years (Kawase et al. 2020).

The second key factor for tackling the paradox of snowfall is changes in winter total precipitation. Global warming can lead to more evaporation from the warmer ocean and moistening of the low atmosphere according to the Clausius-Clapeyron relationship. On the other hand, winter precipitation is controlled by atmospheric circulations, e.g., East Asian winter monsoons in Japan, which are also influenced by global warming. Some global climate models project weakened East Asian winter monsoons due to global warming ( $\mathrm{Hu}$ et al. 2000; Kimoto et al. 2005; Hori and Ueda 2006), which will cause a decrease in winter precipitation along the SoJ and cause an increase in winter precipitation in Japan along the Pacific Ocean (hereafter referred to as the PO) because of the northward shift of extratropical cyclones passing south of Japan (Kawase et al. 2015; Nosaka et al. 2020). The extratropical cyclones also bring heavy snowfall and rainfall over the inland areas of central Japan (Ando and Ueno 2015).

Both the rising temperature levels and the precipitation changes due to global warming strongly depend on the emission scenario. The Intergovernmental Panel on Climate Change (IPCC) Fifth Assessment Report (AR5) mainly evaluated emission scenarios of Representative Concentration Pathways (RCPs). However, few studies have investigated the dependency of climatological changes in snowfall and snow cover on emission scenarios in Japan.

The purpose of this study is to clarify the nonlinear changes in snowfall and snow cover due to global warming using a highresolution regional climate model (RCM). This study analyzes high-resolution regional climate projections under two RCPs with radiative forcing of 2.6 and $8.5 \mathrm{~W} / \mathrm{m}^{2}$ (hereafter referred to as RCP2.6 and RCP8.5), which are the highest and lowest emission scenarios, respectively, in IPCC AR5. First, we show the regionality of climatological changes in snowfall with each emission scenario and focus on two regions, Hokkaido and the Sea of Japan side of eastern Japan. Then, we focus on the relationship between the winter-mean temperature in the present climate and future changes in snowfall and the ratio of snowfall to precipitation in the two regions. Lastly, we discuss future changes in atmospheric circulations producing winter-total precipitation changes.

\section{Experimental design}

Regional climate projections are conducted using a nonhydrostatic regional climate model (Sasaki et al. 2008) with 5 
(a) Model domain

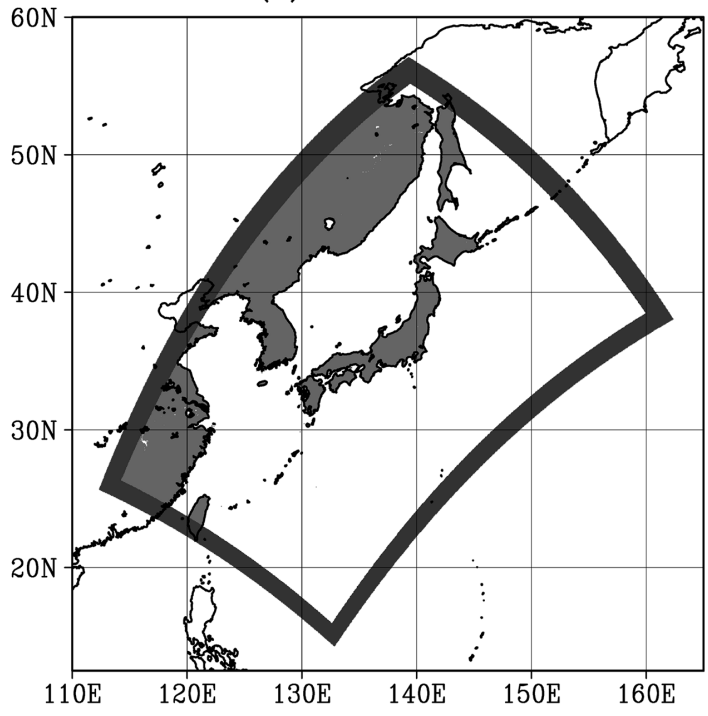

(b) Topography

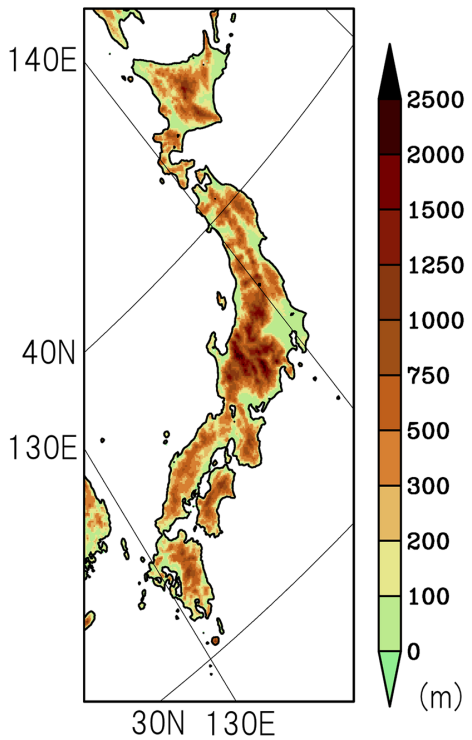

(c) Name of regions

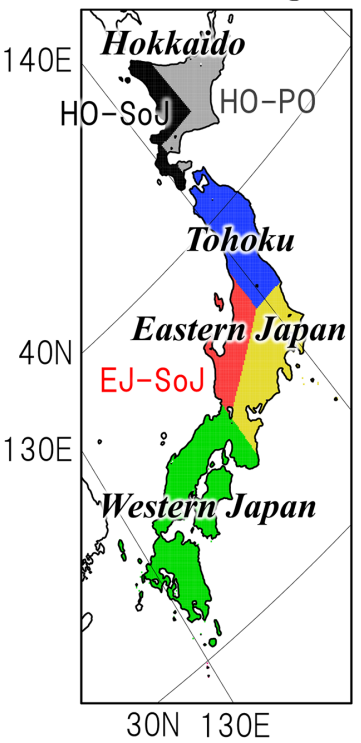

Fig. 1. Model domain, topography of NHRCM05, and names of regions The definitions of specific regions are based on Murata et al. (2015) except for the separation of Hokkaido and Tohoku. HO and EJ represent Hokkaido and eastern Japan, respectively. SoJ and PO represent the Sea of Japan and the Pacific Ocean, respectively.

$\mathrm{km}$ grid spacing (hereafter referred to as NHRCM05). The model domain, topography, and names of regions are shown in Fig. 1. The lateral boundary conditions are time-slice global climate projections using a Meteorological Research Institute atmospheric general circulation model with about $20 \mathrm{~km}$ grid spacing (hereafter referred to as MRI-AGCM20; Mizuta et al. 2012). The details of the experimental designs and specifications of NHRCM05 can be found in Table S1 and Murata et al. (2015), who showed the biases of the surface air temperature and precipitation in NHRCM05 and future changes under RCP8.5. The biases of snow depth in NHRCM05 were evaluated at JMA stations by Sasaki et al. (2013).

Here, we conducted additional future climate projections under RCP2.6. Four patterns of SST changes in RCP2.6 are derived from the same cluster analysis grouping as in RCP8.5, as described by Mizuta et al. (2014) (Fig. S1). Additionally, four initial ensemble experiments were conducted in the historical climate. The simulation periods are 1980-1999 and 2076-2095 in the historical and future climates, respectively. Therefore, we have
DJF mean surface air temperature (a) HIST

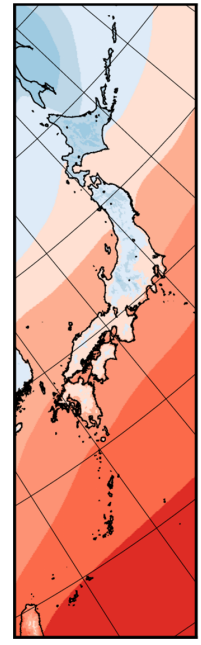

(b) RCP2.6

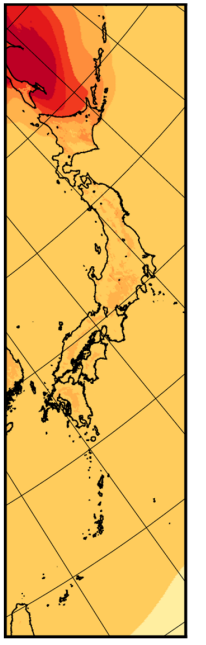

(c) RCP8.5

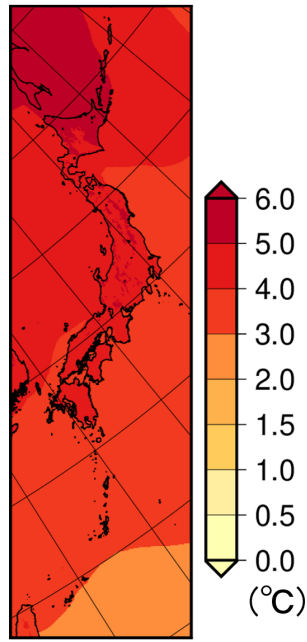

DJF total precipitation (d) HIST

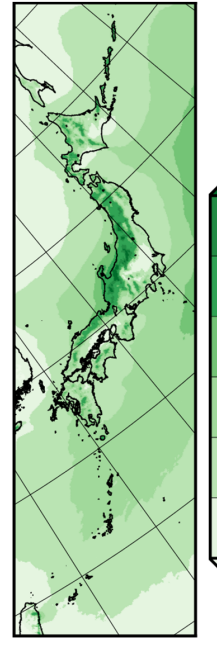

(e) RCP2.6

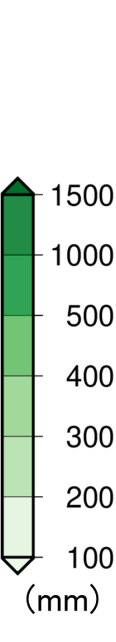

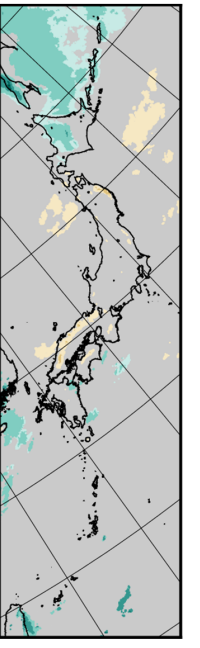

(f) RCP8.5

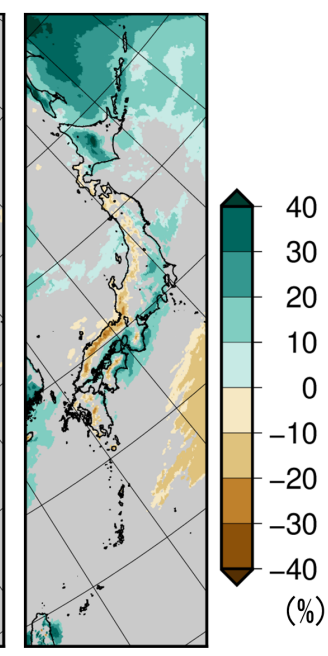

Fig. 2. Climatology and future changes in the 80-year mean DJF surface air temperature and total precipitation under RCP2.6 and RCP8.5. $(\mathrm{a}-\mathrm{c})$ Surface air temperature. $(\mathrm{d}-\mathrm{f})$ total precipitation. Gray-shaded areas represent insignificant changes in precipitation at the $95 \%$ confidence interval, according to the Mann-Whitney U test. All areas show significant changes in surface air temperature, according to the Mann-Whitney U test.

an 80-year historical climate simulation, the RCP2.6 scenario, and the RCP8.5 scenario (hereafter referred to as the HIST, RCP2.6, and RCP8.5 runs, respectively). Note that the RCP2.6 and RCP8.5 runs include variability caused by the uncertainty of future changes in SST patterns, while HIST runs include variability caused by four initial ensembles.

\section{Regional characteristics of future climate chang- es under two scenarios}

\subsection{Surface air temperature and precipitation in winter}

The 80-year-mean winter (December-January-February; DJF) surface air temperature is projected to rise approximately $1.5^{\circ} \mathrm{C}$ and $4-5^{\circ} \mathrm{C}$ under RCP2.6 and RCP8.5, respectively, in most parts of Japan (Fig. 2). The temperature rise in the northern parts of 


\section{Annual total snowfall}
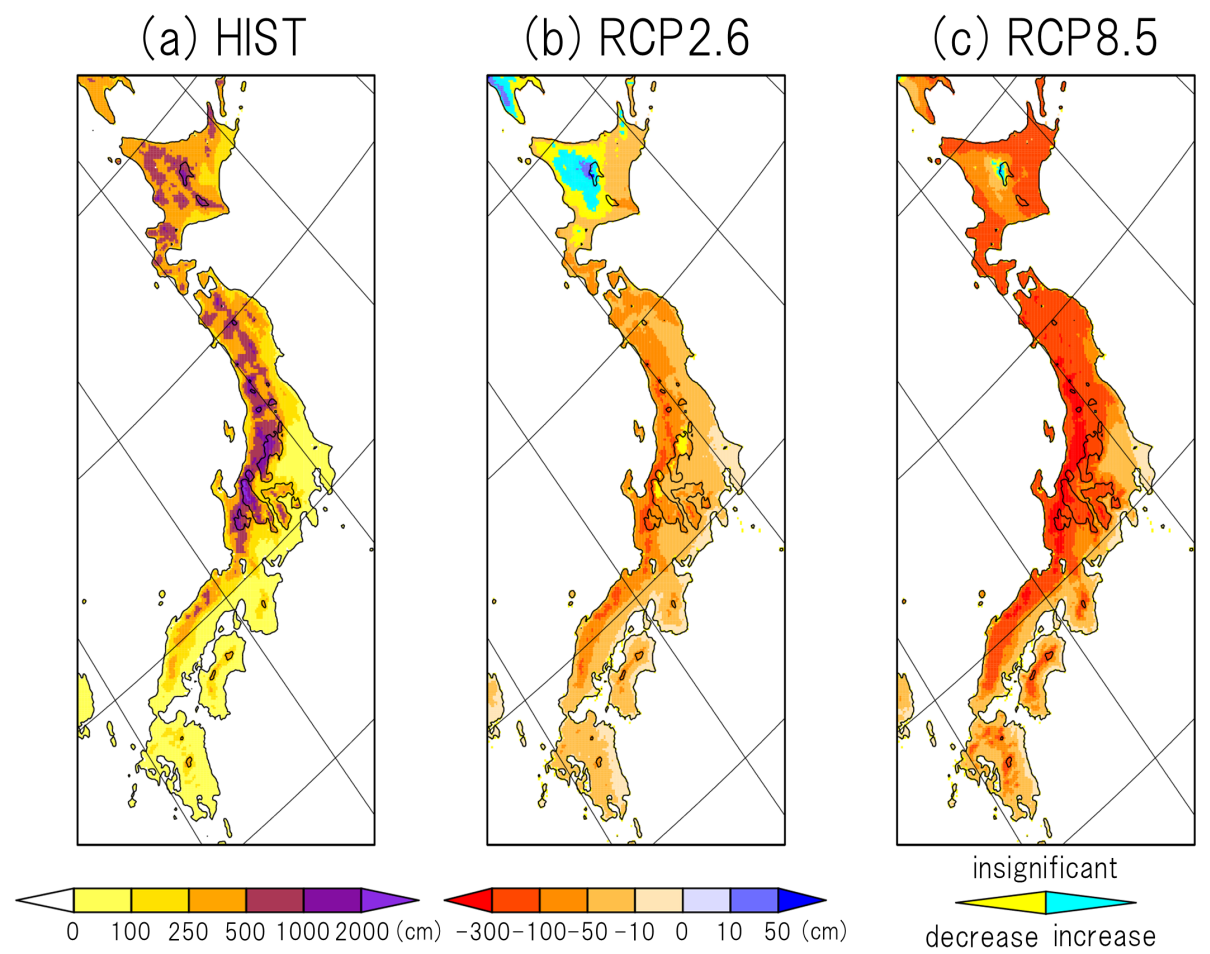

Fig. 3. Climatology and future changes in annual total snowfall. (a) 80-year-mean annual total snowfall in the HIST run. Future changes under (b) RCP2.6 and (c) RCP8.5. Yellow and cyan colors represent the insignificant decrease and increase, respectively, according to the Mann-Whitney U test.

Japan is greater than that in other regions. Over the coastal areas along the Sea of Okhotsk, the winter mean temperature is projected to rise more than $2^{\circ} \mathrm{C}$ and $5.5^{\circ} \mathrm{C}$ under RCP2.6 and $\mathrm{RCP} 8.5$, respectively, which is related to the disappearance of sea ice due to global warming.

Winter precipitation changes are insignificant under RCP2.6 in most parts of Japan. In Hokkaido, winter precipitation significantly increases under both RCP2.6 and RCP8.5. Under RCP8.5, changes in winter precipitation show a clear contrast between the $\mathrm{PO}$ and SoJ sides, which is consistent with the findings of previous studies (e.g., Kawase et al. 2015, 2016; Nosaka et al. 2020). The influence of changes in winter precipitation on snowfall will be discussed in Section 4.

\subsection{Annual and monthly snowfall}

NHRCM05 simulates a horizontal distribution of annual total snowfall corresponding to Japan's topography (Figs. 1b and 3a). Northwesterlies from the Eurasian continent cause a lot of snowfall along the SoJ due to the orographic uplift by Japan's mountains. The snow depth exceeds $600 \mathrm{~cm}$ over mountainous areas in eastern Japan (Fig. S2), which is consistent with observations at Mts. Tateyama (Aoki and Watanabe 2009; Kawase et al. 2018, 2019). Under both scenarios, the annual total snowfall largely decreases over most of Japan except for the inland areas of Hokkaido (Figs. 3b and 3c). Future changes in the annual maximum snow depth are similar to those in the annual total snowfall (Fig. S2).

A comparison of changes in the total snowfall between HIST, RCP2.6, and RCP8.5 clearly shows regional differences in snowfall changes (Fig. 4). Note that Fig. 4 does not consider the statistical significance of the changes. In both scenarios, the annual total snowfall decreases over all of Japan except for Hokkaido (Fig. 4a). The patterns of future changes in snowfall differ depending on the month. In December and January, the monthly total snowfall decreases in all of Japan except for Hokkaido and part of eastern Japan (Figs. 4b and 4c). In February, the total snowfall increases and decreases under RCP2.6 and RCP8.5, respectively, over inland areas in Tohoku and eastern Japan (Fig. 4d). Over Hokkaido along the SoJ, the total snowfall appears to increase in January and February under both scenarios (Figs. 4c and 4d).

The annual maximum and monthly maximum daily snowfall, which are extreme events, increase over several regions in Japan under both RCP2.6 and RCP8.5 (Fig. S3). The enhancement of heavy daily snowfall has been projected over mountainous areas in central Japan due to global warming by Sasai et al. (2019), who indicated that increased cold air mass flux from the continent and more latent heat over the Sea of Japan contributed to the enhancement of extreme snowfall events.

\section{Comparison of changes in snowfall between the SoJ side of eastern Japan and Hokkaido}

Future changes in annual and monthly total snowfall between Hokkaido and the Sea of Japan side of eastern Japan (hereafter referred to as EJ-SoJ) differ considerably. We focus on seasonal variations of the regional pentad mean snowfall in both regions. In Hokkaido, the amount of snowfall under RCP2.6 is comparable to or larger than that under HIST from December to March (Fig. 5a). Under RCP8.5, snowfall substantially decreases before January and after late February. On the other hand, the snowfall is comparable to that of HIST from late January to early February. Peak snowfall is delayed from early December to late January under RCP8.5, which is related to the seasonal variation in the surface air temperature in the future climate and increased winter precipitation. In EJ-SoJ, snowfall amounts decrease from October to April under RCP2.6 (Fig. 5b). Only in late February, snowfall amounts are comparable to those in HIST. Under RCP8.5, snowfall amounts significantly decrease in eastern Japan. Peak snowfall is delayed, but the delay is not as clear as in Hokkaido.

Future changes in seasonal variations in snowfall over EJ-SoJ show a typical response in mid-latitude maritime mountain ranges, 
(a) Annual

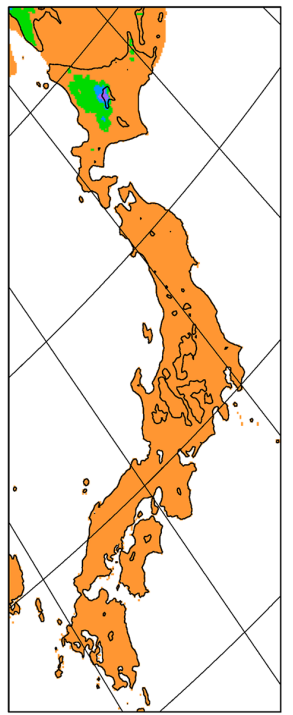

(b) December

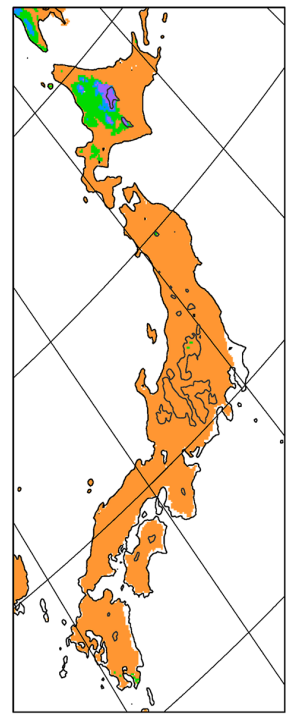

(c) January

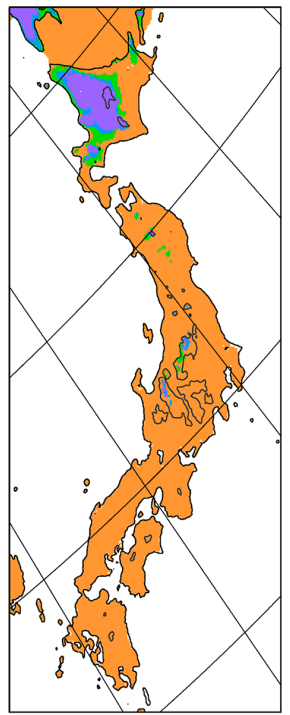

(d) February

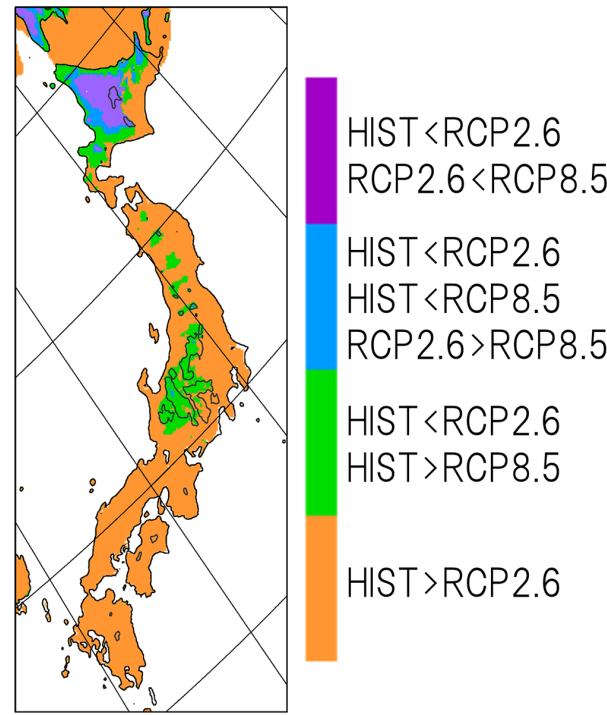

Fig. 4. Patterns of future changes in total snowfall. (a) Annual total snowfall. (b-d) Monthly total snowfall in December, January, and February.
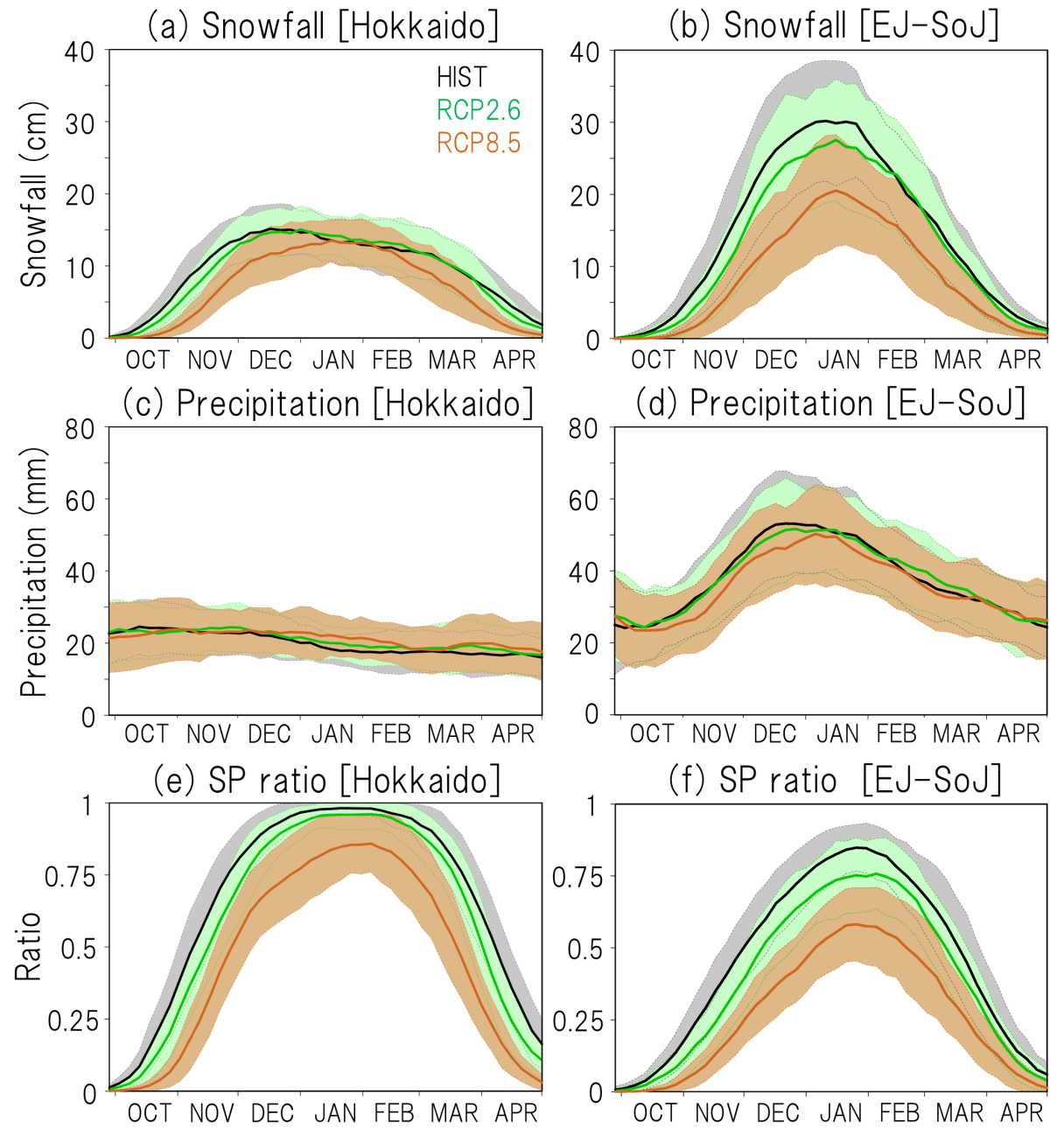

Fig. 5. Seasonal variations of regional pentad mean $(a, b)$ snowfall, $(c, d)$ precipitation, and (e, f) snowfall ratio from October 1 to May 1. (Black) HIST, (green) RCP2.6, and (brown) RCP8.5 runs. The Five-pentad running mean is conducted. Shadings indicate the \pm 1 standard deviation of annual variation calculated by 80-year simulations in each climate. (a, c, d) Hokkaido and (b, d, e) EJ-SoJ. 
while the response in Hokkaido is quite different. The amount of precipitation increases in Hokkaido during the winter due to global warming (Figs. 2d and 5c). On the other hand, decreases in precipitation are simulated over EJ-SoJ, especially under RCP8.5 (Figs. 2d and 5d). In Hokkaido, the ratio of snowfall to precipitation (hereafter referred to as the snowfall ratio) is almost 1 in winter under the present climate and RCP2.6 (Fig. 5e). Even under RCP8.5, the snowfall ratio exceeds 0.75 in Hokkaido, which is comparable to the snowfall ratio in EJ-SoJ under the present climate (Fig. 5f). The increase in precipitation and high snowfall ratio under RCP8.5 results in plentiful snowfall comparable to the present climate in Hokkaido, while the decrease in precipitation and the low snowfall ratio result in a considerable reduction of snowfall in EJ-SoJ (Fig. 5f).

The winter-mean surface air temperature in the present climate is important for comprehending whether snowfall increases or decreases due to global warming. If the surface air temperature is much lower than the freezing point in the present climate, the air temperature is still lower than the freezing point in the future climate. Figure 6 shows scatter diagrams of the winter-mean surface air temperature and future changes in winter total precipitation or snowfall at each grid point under RCP2.6 and RCP8.5. The surface air temperature is below $0^{\circ} \mathrm{C}$ at most grid points in Hokkaido, even under RCP8.5, while the surface air temperature exceeds $0^{\circ} \mathrm{C}$ at most grid points in EJ-SoJ. Precipitation increases in Hokkaido, especially in the temperature range of -10 to $-5^{\circ} \mathrm{C}$ (Fig. 6a), and the percentage of precipitation change exceeds $+40 \%$ at some grid points under RCP8.5. Over EJ-SoJ, no changes in DJF precipitation appear under RCP2.6, and precipitation mostly decreases by $10-20 \%$ under RCP8.5. Over the coldest areas of Hokkaido, the enhancement of DJF precipitation results in a considerable increase in snowfall under RCP8.5 (Fig. 6b). In EJ-SoJ, no increase in snowfall is projected, even in the low-temperature range where snowfall increases in Hokkaido. Snowfall drastically decreases over areas where the air temperature is higher than $0^{\circ} \mathrm{C}$ in EJ-SoJ.

It is noteworthy that snowfall rapidly decreases when the mean air temperature is around $-5^{\circ} \mathrm{C}$ in Hokkaido under RCP8.5. This rapid reduction occurs in Hokkaido along the PO (Fig. S4). Generally, extratropical cyclones passing to the south of Hokkaido bring heavy snowfall as well as warm air advection over Hokkaido along the PO. In the future climate, extratropical cyclones will bring air that is warmer than that of the present climate, and the air temperature will rise above the freezing point, resulting in a large reduction in snowfall, even if the winter-mean temperature is lower than $0^{\circ} \mathrm{C}$.

\section{Atmospheric circulation changes in winter}

As discussed in Section 4, future changes in snowfall not only are controlled by the rising temperature, which reduces the snowfall ratio, but they are also influenced by precipitation changes in Japan. The difference in precipitation changes between EJ-SoJ and Hokkaido cannot be explained by moistening due to warming (Fig. 6). Atmospheric circulation changes due to global warming can play a role in future precipitation changes.

Under RCP2.6, significant cyclonic and low-height anomalies at $850 \mathrm{hPa}$ are projected over the Aleutian Islands by MRIAGCM20, the boundary conditions of NHRCM05 (Fig. 7b). The westerly anomaly prevails over Hokkaido, while wind anomalies are insignificant in eastern and western Japan. Under RCP8.5, the cyclonic and anticyclonic anomalies clearly appear north and south of the Aleutian low, respectively, indicating the poleward shift of the Aleutian low (Fig. 7c). Ito et al. (2020) showed a similar pattern for future projections with Coupled Model Intercomparison Project Phase (CMIP5) multi-models. The southeasterly and westerly anomalies over eastern Japan and Hokkaido mean a weakened northwesterly and a strengthened westerly, respectively (Fig. 7a), resulting in the inhibition and enhancement of the topographic updraft of the Japanese mountains (Fig. S5).

Extratropical cyclones also bring snowfall and rainfall to Japan. Future changes in extratropical cyclone activities are eval- (a) Precipitation change and temperature

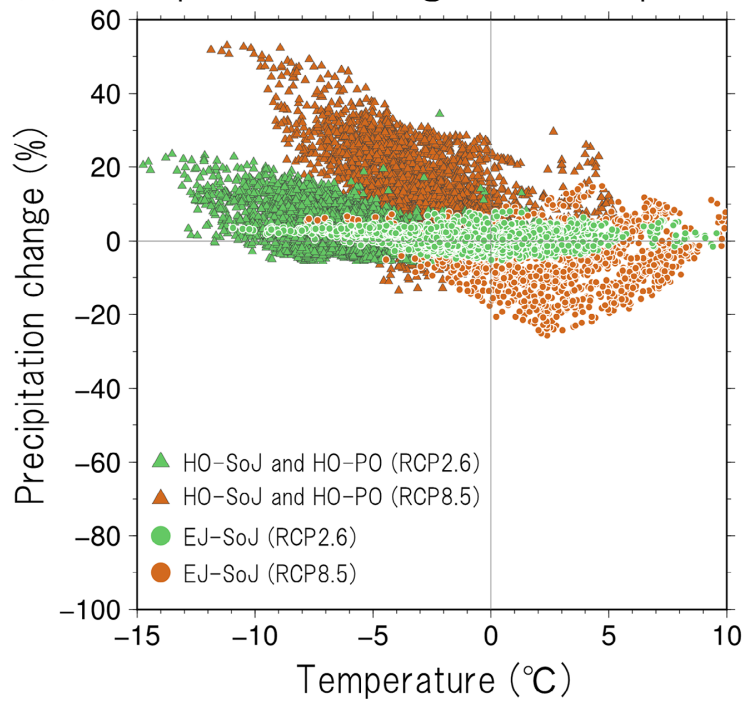

(b) Snowfall change and temperature

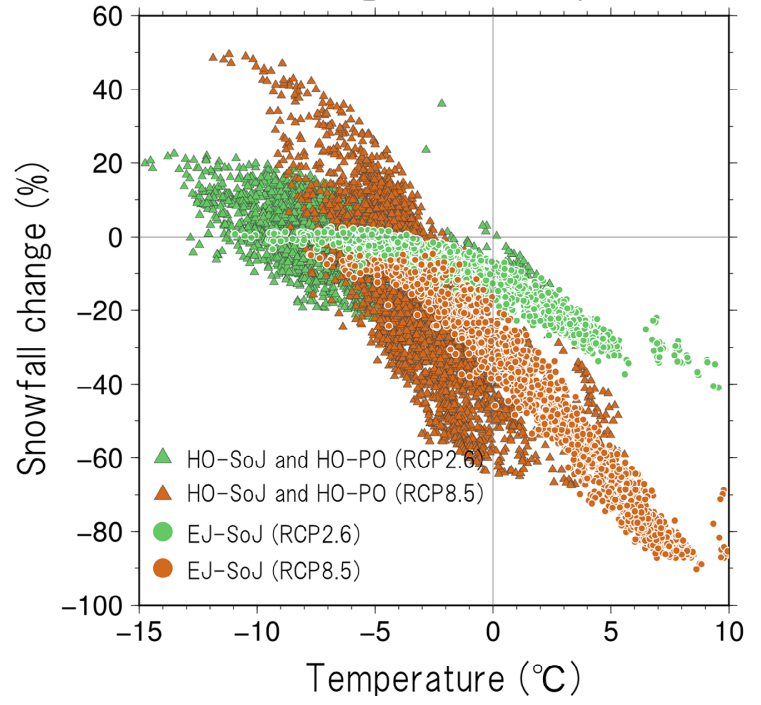

Fig. 6. Scatter diagrams of the DJF mean surface temperature in the future climate and future changes in total precipitation and total snowfall. (a) Precipitation and surface air temperature and (b) snowfall and surface air temperature. Green and brown colors represent RCP2.6 and RCP8.5, respectively. Triangles and circles represent Hokkaido and EJ-SoJ, respectively.

uated using eddy heat fluxes $\left(\mathrm{v}^{\prime} \mathrm{T}^{\prime}\right)$ at the synoptic time scale $(2.5-$ 8.0 days) at $850 \mathrm{hPa}$. Here, $\mathrm{v}^{\prime}$ and $\mathrm{T}^{\prime}$ mean high-frequency components of meridional wind and air temperature, respectively. Extratropical cyclone activity weakens southeast and east of Japan under RCP2.6 (Fig. 7d). Under RCP8.5, extratropical cyclone activity strengthens and weakens south and north of the climatologically active area, respectively, which indicates a northward shift of extratropical cyclone paths (Fig. 7e). Extratropical cyclone activity strengthened around the northern part of Japan under RCP8.5. This can directly contribute to increased precipitation over Hokkaido, while this signal is not statistically significant according to the Student t-test.

Global warming modulates the thermal contrast between the $\mathrm{PO}$ and the Eurasian continent in the winter, which contributes to changes in the winter monsoon. Hori and Ueda (2006) pointed out that global warming weakened the winter monsoon, accompanied by the anticyclonic anomaly over the North Pacific corresponding to the Aleutian low. It is difficult to distinguish between the effects 

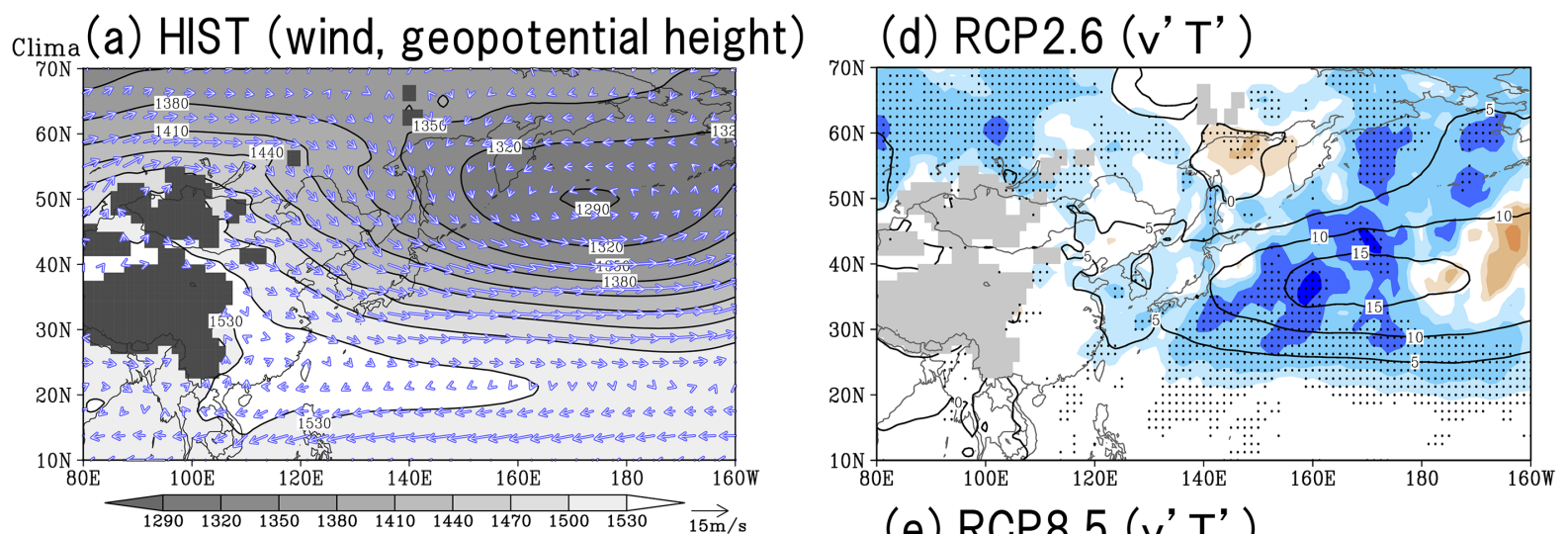

(b) RCP2.6

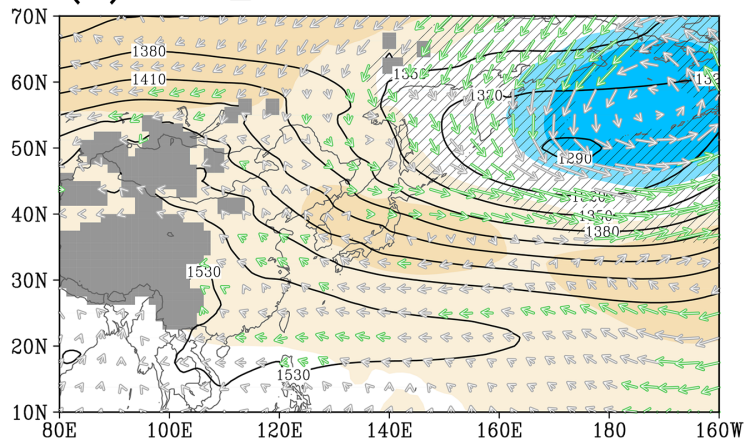

(c) RCP8.5
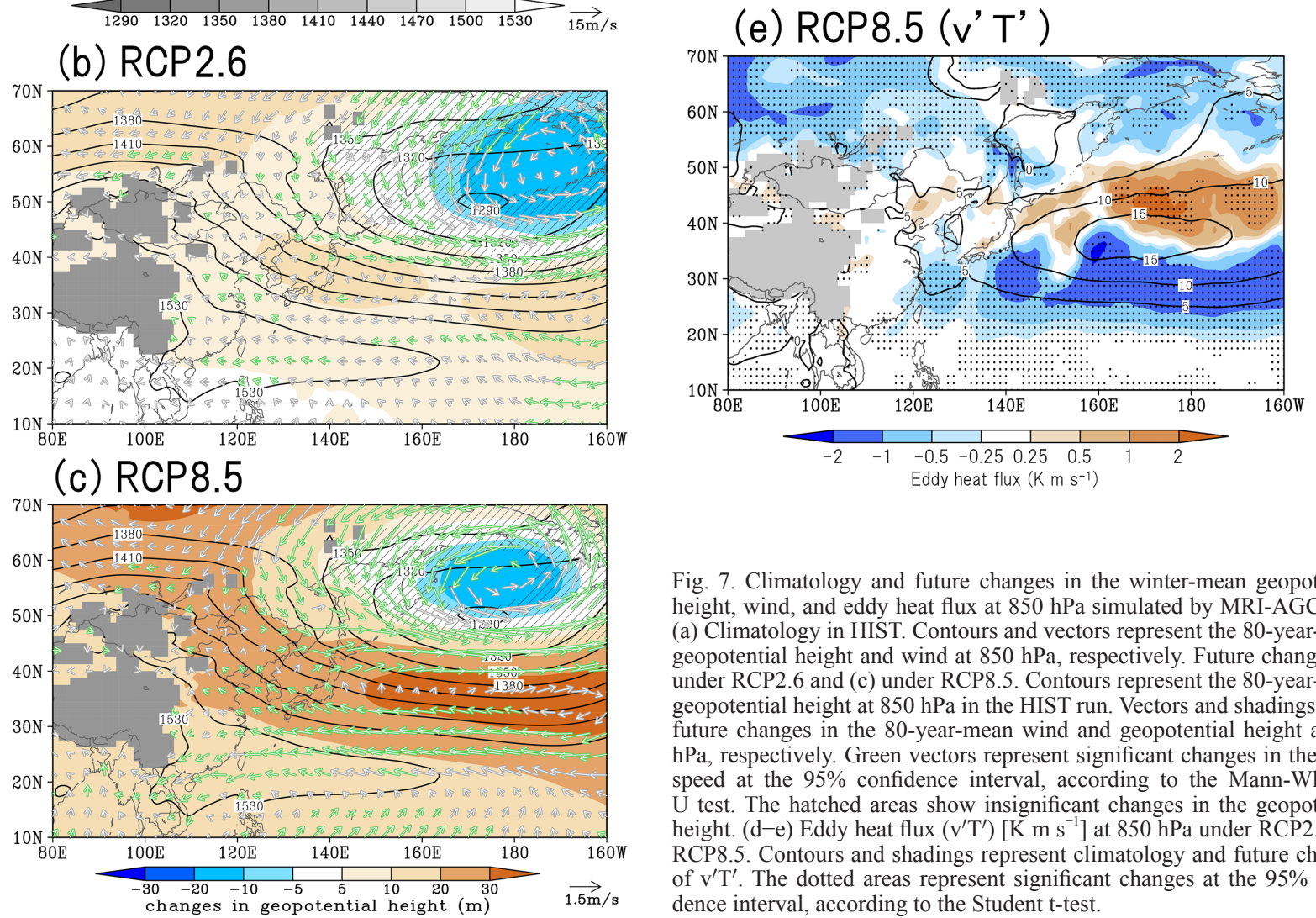

Fig. 7. Climatology and future changes in the winter-mean geopotential height, wind, and eddy heat flux at $850 \mathrm{hPa}$ simulated by MRI-AGCM20. (a) Climatology in HIST. Contours and vectors represent the 80-year-mean geopotential height and wind at $850 \mathrm{hPa}$, respectively. Future changes (b) under RCP2.6 and (c) under RCP8.5. Contours represent the 80-year-mean geopotential height at $850 \mathrm{hPa}$ in the HIST run. Vectors and shadings show future changes in the 80 -year-mean wind and geopotential height at 850 $\mathrm{hPa}$, respectively. Green vectors represent significant changes in the wind speed at the $95 \%$ confidence interval, according to the Mann-Whitney $\mathrm{U}$ test. The hatched areas show insignificant changes in the geopotential height. (d-e) Eddy heat flux $\left(\mathrm{v}^{\prime} \mathrm{T}^{\prime}\right)\left[\mathrm{K} \mathrm{m} \mathrm{s}^{-1}\right]$ at $850 \mathrm{hPa}$ under RCP2.6 and RCP8.5. Contours and shadings represent climatology and future changes of $\mathrm{v}^{\prime} \mathrm{T}^{\prime}$. The dotted areas represent significant changes at the $95 \%$ confidence interval, according to the Student t-test.

of future changes in the Aleutian low and the winter monsoon because they interact with each other (Luo and Zhang 2015). However, at least the anticyclonic anomaly, likely caused by changes in the Aleutian low, and the winter monsoon are projected by CMIP5 models under RCP8.5 with some inter-model variability (Ito et al. 2020). Therefore, understanding the uncertainty in atmospheric circulation changes due to global warming is important for assessing regional-scale snowfall changes in Japan as well as the thermal impact on snowfall.

\section{Summary}

Regional characteristics of future changes in snowfall were investigated using a regional climate model with $5 \mathrm{~km}$ grid spacing under RCP2.6 and RCP8.5 scenarios. Future changes in snowfall differ considerably between Hokkaido and the SoJ side of eastern Japan. Under both scenarios, the annual total snowfall will decrease in most parts of Japan, while snowfall amounts will increase over inland areas of Hokkaido from January to February. The winter snowfall total increases over the cold regions of Hokkaido, while it decreases along the SoJ in eastern Japan under both scenarios, even if the winter-mean temperature is the same as that in Hokkaido. Changes in atmospheric circulation connected to a poleward shift of the Aleutian low cause the enhancement and the inhibition of winter precipitation in Hokkaido and eastern Japan, respectively, resulting in a peculiar seasonal variation of snowfall in Hokkaido as compared with those of the SoJ in eastern Japan. Therefore, in addition to the thermal effects on snowfall, the change in atmospheric circulation due to global warming is important for future changes in regional-scale snowfall and snow cover in Japan.

\section{Acknowledgments}

We thank two anonymous reviewers for their helpful comments. This research was supported by JSPS KAKENHI Grant Number $19 \mathrm{H} 01377$ and by the Integrated Research Program for Advancing Climate Models (TOUGOU), Grant Number JPMXD 0717935561, from the Ministry of Education, Culture, Sports, Science and Technology (MEXT), Japan.

Edited by: S. Nishizawa 


\section{Supplements}

Supplement 1: One table and five supplemental figures are included.

\section{References}

Ando, N., and K. Ueno, 2015: Occurrence tendency of heavy rainfall or snowfall in the inland district of Japan in winter. Seppyo, 77, 397-410 (in Japanese with an English abstract).

Aoki, K., and K. Watanabe, 2009: Measurements of atmospheric aerosol at Mt. Tateyama, Japan. Earozoru Kenkyu, 24, 112116 (in Japanese with an English abstract).

Brown, R. D., and P. Mote, 2009: The response of Northern Hemisphere snow cover to a changing climate. J. Climate, 22, 2124-2145.

Hara, M., T. Yoshikane, H. Kawase, and F. Kimura, 2008: Estimation of the impact of global warming on snow depth in Japan by the pseudo-global-warming method. Hydrol. Res. Lett., 2, 61-64.

Hock, R., G. Rasul, C. Adler, B. Cáceres, S. Gruber, Y. Hirabayashi, M. Jackson, A. Kääb, S. Kang, S. Kutuzov, Al. Milner, U. Molau, S. Morin, B. Orlove, and H. Steltzer, 2019: High Mountain Areas. IPCC Special Report on the Ocean and Cryosphere in a Changing Climate, H.-O. Pörtner et al., Eds., Cambridge University Press, Cambridge, UK.

Hori, M. E., and H. Ueda, 2006: Impact of global warming on the East Asian winter monsoon as revealed by nine coupled atmosphere-ocean GCMs. Geophys. Res. Lett., 33, L03713.

Hosaka, M., D. Nohara, and A. Kitoh, 2005: Changes in snow cover and snow water equivalent due to global warming simulated by a $20 \mathrm{~km}$-mesh global atmospheric model. SOLA, 1, 93-96.

Hu, Z.-Z., L. Bengtsson, and K. Arpe, 2000: Impact of global warming on the Asian winter monsoon in a coupled GCM. $J$. Geophys. Res., 105, 4607-4624.

Inoue, S., and K. Yokoyama, 2003: Estimates of snowfall depth, maximum snow depth, and snow pack environments under global warming in Japan from five sets of predicted data. $J$. Agri. Meteor., 59, 227-236.

Ito, R., T. Ose, H. Endo, R. Mizuta, K. Yoshida, A. Kitoh, and T. Nakaegawa, 2020: Seasonal characteristics of future climate change over Japan and the associated atmospheric circulation anomalies in global model experiments. Hydrol. Res. Lett., 14, 130-135.

Kawase, H., M. Hara, T. Yoshikane, N. N. Ishizaki, F. Uno, H. Hatsushika, and F. Kimura, 2013: Altitude dependence of future snow cover changes over Central Japan evaluated by a regional climate model. J. Geophys. Res., 118, doi:10.1002/ 2013JD020429.

Kawase, H., H. Sasaki, A. Murata, M. Nosaka, and N. N. Ishizaki, 2015: Future changes in winter precipitation around Japan projected by ensemble experiments using NHRCM. $J$. Meteor. Soc. Japan, 93, 571-580.

Kawase, H., A. Murata, R. Mizuta, H. Sasaki, M. Nosaka, M. Ishii, and I. Takayabu, 2016: Enhancement of heavy daily snowfall in central Japan due to global warming as projected by large ensemble of regional climate simulations. Climatic Change, 139, 265-278.

Kawase, H., A. Yamazaki, H. Iida, K. Aoki, H. Sasaki, A. Murata, and M. Nosaka, 2018: Simulation of extremely small amounts of snow observed at high elevations over the Japanese Northern Alps in the 2015/16 winter. SOLA, 14, 39-45, doi:10.2151/sola.2018-007.

Kawase, H., H. Iida, K. Aoki, W. Shimada, M. Nosaka, A. Murata, and H. Sasaki, 2019: Comparison of snow cover observations along the Tateyama-Kurobe Alpine route with snow cover simulations using the non-hydrostatic regional climate model (NHRCM) with different horizontal resolutions. $J$. Geogr. (Chigaku Zasshi), 128, 77-92 (in Japanese with an
English abstract).

Kawase, H., T. Yamazaki, S. Sugimoto, T. Sasai, R. Ito, T. Hamada, M. Kuribayashi, M. Fujita, A. Murata, M. Nosaka, and H. Sasaki, 2020: Changes in extremely heavy and light snowcover winters due to global warming over high mountainous areas in central Japan. Prog. Earth Planet. Sci., 10, doi 10.1186/s40645-020-0322-x.

Kimoto, M., 2005: Simulated change of the East Asian circulation under global warming scenario. Geophys. Res. Lett., doi 10.1029/2005GL023383.

Luo, X., and Y. A. Zhang, 2015: The linkage between upper-level jet streams over East Asia and East Asian winter monsoon variability. J. Climate, 28, 9013-9028, doi:10.1175/JCLID-15-0160.1.

Meredith, M., M. Sommerkorn, S. Cassotta, C. Derksen, A. Ekaykin, A. Hollowed, G. Kofinas, A. Mackintosh, J. MelbourneThomas, M. M. C. Muelbert, G. Ottersen, H. Pritchard, and E. A. G. Schuur, 2019: Polar Regions. IPCC Special Report on the Ocean and Cryosphere in a Changing Climate, H.-O. Pörtner et al., Eds., Cambridge University Press, Cambridge, UK.

Mizuta, R., H. Yoshimura, H. Murakami, M. Matsueda, H. Endo, T. Ose, K. Kamiguchi, M. Hosaka, M. Sugi, S. Yukimoto, S. Kusunoki, and A. Kitoh, 2012: Climate simulations using the MRI-AGCM3.2 with 20-km grid. J. Meteor. Soc. Japan, 90A, 233-258.

Mizuta, R., O. Arakawa, T. Ose, S. Kusunoki, H. Endo, and A. Kitoh, 2014: Classification of CMIP5 future climate responses by the tropical sea surface temperature changes. SOLA, 10, 167-171, doi:10.2151/sola.2014-035.

Murata, A., H. Sasaki, H. Kawase, M. Nosaka, M. Oh'izumi, T. Kato, T. Aoyagi, F. Shido, K. Hibino, S. Kanada, A. SuzukiParker, and T. Nagatomo, 2015: Projection of future climate change over Japan in ensemble simulations with a highresolution regional climate model. SOLA, 11, 90-94.

Nosaka, M., M. Ishii, H. Shiogama, R. Mizuta, A. Murata, H. Kawase, and H. Sasaki, 2020: Scalability of future climate changes across Japan examined with large-ensemble simulations at $+1.5 \mathrm{~K},+2 \mathrm{~K}$, and $+4 \mathrm{~K}$ global warming levels. Prog. Earth Planet. Sci., 7, doi:10.1186/s40645-020-00341-3.

Räisänen, J., and K. Eklund, 2012: Twenty-first century changes in snow climate in northern Europe: A high-resolution view from ENSEMBLES regional climate models. Climate Dyn., 38, 2575-2591, doi:10.1007/s00382-011-1076-3.

Rasmussen, R., C. Liu, K. Ikeda, D. Gochis, D. Yates, F. Chen, M. Tewari, M. Barlage, J. Dudhia, W. Yu, K. Miller, K. Arsenault, V. Grubisic, G. Thompson, and E. Gutmann, 2011: High-resolution coupled climate runoff simulations of seasonal snowfall over Colorado: A process study of current and warmer climate. J. Climate, 24, 3015-3048.

Rasmussen, R., K. Ikeda, C. Liu, D. Gochis, M. Clark, A. Dai, E. Gutmann, J. Dudhia, F. Chen, M. Barlage, D. Yates, and G. Zhang, 2014: Climate change impacts on the water balance of the Colorado headwaters: High-resolution regional climate model simulations. J. Hydrometeorol., 15, 1091-1116, doi:10.1175/JHM-D-13-0118.1.

Sasai, T., H. Kawase, Y. Kanno, J. Yamaguchi, S. Sugimoto, T. Yamazaki, H. Sasaki, M. Fujita, and T. Iwasaki, 2019: Future projection of extreme heavy snowfall events with a $5-\mathrm{km}$ large ensemble regional climate simulation. J. Geophys. Res., 124, 13975-13990.

Sasaki, H., K. Kurihara, I. Takayabu, and T. Uchiyama, 2008: Preliminary experiments of reproducing the present climate using the non-hydrostatic regional climate model. SOLA, 4 , 25-28.

Sasaki, H., K. Kurihara, A. Murata, M. Hanafusa, and M. Oh'izumi, 2013: Future changes of snow depth in a non-hydrostatic regional climate model with bias correction. SOLA, 9, 5-8.

Manuscript received 15 July 2020, accepted 13 November 2020

SOLA: https://www.jstage.jst.go.jp/browse/solal 